\title{
Modeling the spatio-temporal changes in land uses and its impacts on ecosystem services in Northeast China over 2000-2050
}

\author{
XIA Tian ${ }^{1,2},{ }^{*}$ WU Wenbin ${ }^{1}$, ZHOU Qingbo ${ }^{1}$, TAN Wenxia², Peter H. VERBURG ${ }^{3}$, \\ YANG Peng ${ }^{1}$, YE Liming ${ }^{4,5}$ \\ 1. Key Laboratory of Agri-informatics, Ministry of Agriculture / Institute of Agricultural Resources and Regional \\ Planning, Chinese Academy of Agricultural Sciences, Beijing 100081, China; \\ 2. Key Laboratory for Geographical Process Analysis \& Simulation, Hubei Province / College of Urban \& En- \\ vironmental Science, Central China Normal University, Wuhan 430079, China; \\ 3. Institute for Environmental Studies, VU University Amsterdam, 1081 HV Amsterdam, The Netherlands; \\ 4. CAAS-UGent Joint Laboratory of Global Change and Food Security / Institute of Agricultural Resources and \\ Regional Planning, Chinese Academy of Agricultural Sciences, Beijing 100081, China; \\ 5. Department of Geology (WE13), Ghent University, 9000 Gent, Belgium
}

\begin{abstract}
Land use and its dynamics have attracted considerable scientific attention for their significant ecological and socioeconomic implications. Many studies have investigated the past changes in land use, but efforts exploring the potential changes in land use and implications under future scenarios are still lacking. Here we simulate the future land use changes and their impacts on ecosystem services in Northeast China (NEC) over the period of 2000-2050 using the CLUE-S (Conversion of Land Use and its Effects at Small regional extent) model under the scenarios of ecological security (ESS), food security (FSS) and comprehensive development (CDS). The model was validated against remote sensing data in 2005. Overall, the accuracy of the CLUE-S model was evaluated at $82.5 \%$. Obtained results show that future cropland changes mainly occur in the Songnen Plain and the Liaohe Plain, forest and grassland changes are concentrated in the southern Lesser Khingan Mountains and the western Changbai Mountains, while the Sanjiang Plain will witness major changes of the wetlands. Our results also show that even though CDS is defined based on the goals of the regional development plan, the ecological service value (ESV) under CDS is RMB 2656.18 billion in 2050. The ESV of CDS is lower compared with the other scenarios. Thus, CDS is not an optimum scenario for eco-environmental protection, especially for the wetlands, which should be given higher priority for future development. The issue of coordination is also critical in future development. The results can help to assist structural adjustments for agriculture and to guide policy interventions in NEC.
\end{abstract}

Received: 2017-03-13 Accepted: 2017-09-12

Foundation: Agricultural Outstanding Talents Research Foundation of Ministry of Agriculture (MOA); Key Laboratory of Agri-Informatics Foundation of MOA No.2015001; Natural Science Foundation of Hubei Province No.2016CFB558; The Fundamental Research Funds for the Central Universities, No.CCNU15A05058

Author: Xia Tian (1981-), Associate Professor, specialized in remote sensing monitoring and simulation of the influence of global changes on agriculture. E-mail: xiatian@mail.ccnu.edu.cn

"Corresponding author: Wu Wenbin, Professor, E-mail: wuwenbin@caas.cn 
Keywords: Northeast China; land use; spatio-temporal change; scenario; ecosystem service

\section{Introduction}

Land use/land cover change (LUCC) has becoming an important topic in the field of global change research (Lambin et al., 2011). Located at relatively high latitudes (from about $39^{\circ}$ to $53^{\circ} \mathrm{N}$ ), Northeast China (NEC) is one of the most important food production regions in China. The NEC is climate-sensitive and has been identified as one of the main areas most susceptible to climate change ( $\mathrm{Li}$ et al., 2012). It also experienced tremendous socio-economic dynamics over the past several decades. All these together have driven obvious changes in land use, particularly for the class of cropland in NEC. For instance, rice planting areas have expanded quickly from $3 \%$ to $13 \%$ of China's total production of rice over the past 30 years (Xia et al., 2016). The NEC is thus among the global hot-spot regions of LUCC studies.

There has been much research to investigate the past LUCC dynamics and environmental consequences in NEC (Chen et al., 2001; Wang et al., 2006; Xia et al., 2014). Indeed, these profound changes in LUCC will continuously move forward in pervasive ways over the next decades. Unfortunately, despite the importance of these changes for human-environment systems, we have little knowledge about the future LUCC (Shearer, 2005; Xu et al., 2015; Zhang et al., 2015; 2016). Although statistical and remote sensing methods are commonly used to explore the spatio-temporal processes of LUCC ( Vliet et al., 2013; Roy et al., 2015; Tian 2015), they are either targeting at specifically small regions or focusing on the past LUCC. Spatially explicit modeling techniques are thus emerging as an alternative to depict the future changes in LUCC at regional scales (Verburg et al., 2009). Because the future has not happened, it offers no facts or testimonies, and provides no means for immediate verification. Uncertainties in social, political and economic development both globally and regionally make it not possible to predict future changes in land use. Instead, it is possible to explore what might happen given certain assumptions about societal developments and environmental changes through the construction of scenarios. Thus, scenario-based modeling provides an appropriate tool to develop plausible visions of future pathways of land use (Shearer, 2005).

During recent years a number of scenario studies have been conducted at a wide range of scales to unravel and assess the possible future land use changes. However, these studies are more concerned about the quantity and location changes in land use under different climate change scenarios (David, 2007; Wang et al., 2015). Few have been done to understand the eco-environmental effects of future land use changes in NEC. This hinders a clear impact assessment of future land use changes, and makes it difficult to work out a trade-off between rational utilization of land resources and better protection of the environment. The integrated impact assessment of future LUCC on ecosystem service is gaining increasing attention in future scenario studies (Liu et al., 2010; Song et al., 2015).

This study thus aims firstly to model the spatio-temporal changes in land use in NEC under future scenarios. More attention is paid to investigate the conversion between cropland and other land use types. Secondly, ecosystem service values are evaluated to quantitatively assess the impacts of different future land use changes. Improved foresight of land use change and its impact can help to better inform policy decisions (Verburg et al., 2006, 2010; 
Bonilla-Moheno et al., 2012; Letourneau et al., 2012; Stürck et al., 2015).

The study area is located in the northeast of China $\left(115^{\circ} 05^{\prime} \mathrm{E}-135^{\circ} 02^{\prime} \mathrm{E}, 38^{\circ} 40^{\prime} \mathrm{N}-\right.$ $53^{\circ} 34^{\prime} \mathrm{N}$ ) which consists of the provinces of Liaoning, Jilin, and Heilongjiang (Figure 1). NEC occupies a land mass of $791,800 \mathrm{~km}^{2}$, of which $264,400 \mathrm{~km}^{2}$ is cropland, taking a share of $16.5 \%$ of the total cropland area in China. Humid and semi-humid climates prevail in NEC (Chen et al., 2012; Li et al., 2012). The mean annual air temperature ranges from -4.2 to $10.9^{\circ} \mathrm{C}$. Most of the region has a base- $10^{\circ} \mathrm{C}$ active accumulated temperature of 1500-3600 degree-days, a frost-free period of 140-170 days, and precipitation of $500-800 \mathrm{~mm}(60 \%$ of the rainfall is concentrated during July-September) (Duan et al., 2016). The main soil types in the northern part are chernozem, meadow soil, and albic soil, while in the southern part it is mainly dark-brown soil. Favor-

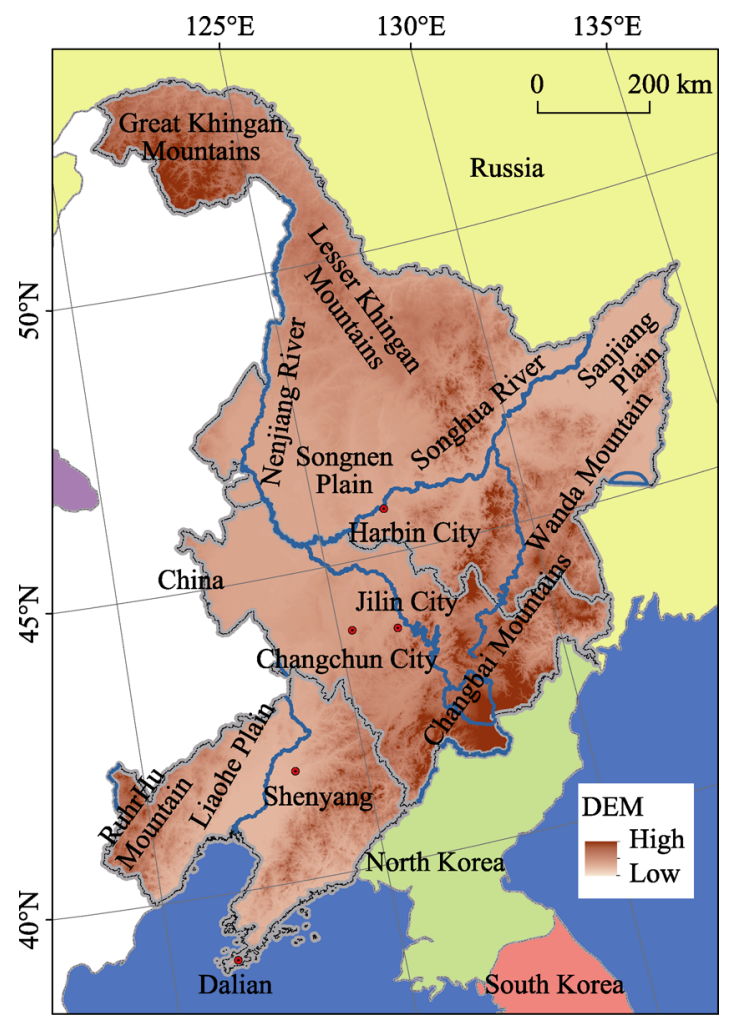

Figure 1 Map of Northeast China able conditions, such as well-built irrigation facilities, suitable climate and fertile black soil, have made NEC the most important base for food production in China.

\section{Methods and data}

\subsection{Simulation of future land use changes}

In this study, the well-known CLUE-S (Conversion of Land Use and its Effects at Small regional extent) model was used to simulate the future changes in land use in NEC. The CLUE-S model uses systems theory to deal with the competition between different land use types (Verburg et al., 2002). The CLUE-S model includes a nonspatial module and a spatial module (Figure 2). The nonspatial module calculates the annual area of demand for land at different target scenarios through an analysis of the

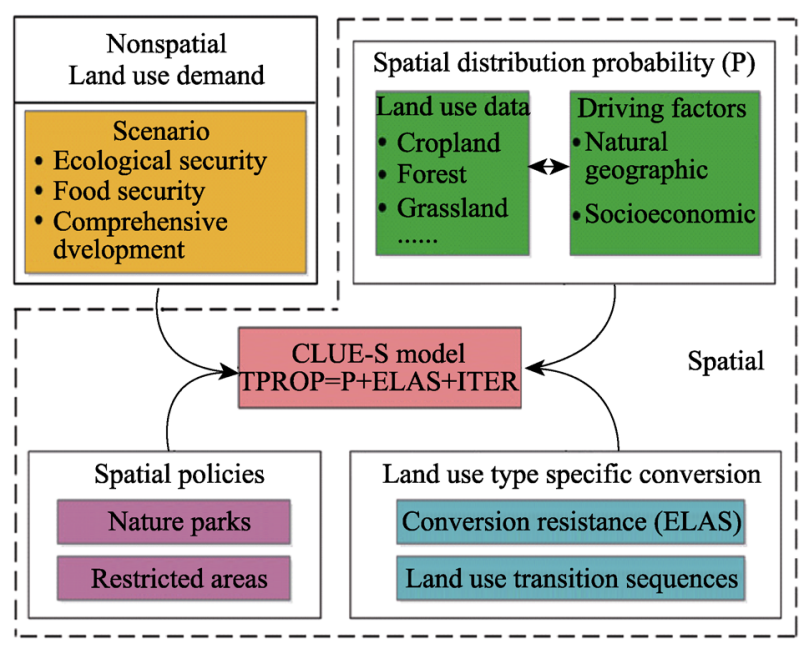

Figure 2 CLUE-S model structure 
drivers of change for natural environment, socio-economy and policies. The demand for different land use types is then allocated to individual grid cells based on the spatial module. In contrast to other models, the CLUE-S model is characterized by its multiscale capability, which can better serve our purpose in combining geophysical and socio-economic parameters to model land use changes under different scenarios (Verburg et al., 2006). In addition, the CLUE-S model had been used to simulated land use changes in many parts of the world (such as Europe, Brazil, Southeast Asia, and China). The model can be used to simulate the spatio-temporal patterns of LUCC for 30-50 years into the future at variable scales ( Verburg and Overmars, 2009; Barreto et al., 2013; Jiang et al., 2016).

The spatial module is based on spatial distribution probability, land use conversion rules and land use pattern in the year of baseline. The calculation of spatial distribution probability of each land use type is the core of the model simulation. Using binary logistic regression to explore the causal relationship between predetermined variables and changes in land use, the land use spatial distribution probability is calculated using the formula:

$$
\operatorname{Logit}\left(P_{i}\right)=\ln \left(P_{i}\right) /\left(1-P_{i}\right)=\beta_{0}+\beta_{1} X_{1, i}+\beta_{2} X_{2, i}+\ldots+\beta_{n} X_{n, i}
$$

where $P_{i}$ is the probability for a grid cell being in land use type $i$, and $X_{i}$ and $n$ are selected driving factors, either physical or socio-economic. Coefficients $(\beta)$ are estimated through binary logistic regression, using the grid-based land use data as the dependent variable and the selected driving factors as independent variables. In addition, space allocation is achieved based on the land use requirements with total probability (Geoghegan et al., 2001; Serneels et al., 2001). The total probability $\left(T_{P R O P}, u\right)$ of grid cell $i$ in land use type $u$ is given by:

$$
T_{P R O P} P_{i, u}=P_{i, u}+E L A S_{u}+\text { ITER }_{u}
$$

where $P_{i, u}$ is the suitability of location $i$ for land use type $u$ (based on the logit model); $E L A S_{u}$ is the conversion elasticity for land use type $u$, which is land use type specific elasticity to change value; and $I T E R_{u}$ is an iteration variable specific to land use type $u$, which is an indicator of the relative competitive strength of the land use type.

The ELAS value indicates the stability of land use conversions, which means the degree of difficulty for one land use type to be converted to other land use types for a certain period of time. For example, cropland can easily be converted to built-up land, while the reverse is difficult. The ELAS parameters range from 0 (easy conversion) to 1 (irreversible change) (Verburg et al., 2002). ELAS values were determined using expert knowledge based on past model behaviors observed (Table 1). Moreover, ITER is another important parameter of the total probability distribution of the model. The distribution area of the land use types is compared with the statistical area of land use (demand data) at the end of each iteration of CLUE-S model runs. If the area of the distribution of land use is less than the statistical area, the model increases the value of ITER; otherwise, it reduces the value of ITER and reallocates the land use area for each land use type.

Table 1 Parameter settings of ELAS

\begin{tabular}{cccccccc}
\hline Land use type & Cropland & Forest & Grassland & Water body & Built-up & Wetland & Unused land \\
\hline ELAS & 0.6 & 0.8 & 0.5 & 0.9 & 0.9 & 0.7 & 0.4 \\
\hline
\end{tabular}

In addition, a conversion matrix is used to control the transformation between different land use types. Land use conversion rules are used to define whether land use type conver- 
sions between various land use types can be achieved. Conversion rules are specified in a conversion matrix, in which a value of 1 means that one land use type can be converted to the other types, and 0 means that one type cannot be converted to the other types. The land use type conversion matrix is set according to the practical situations in NEC.

The model application was designed to run over a period of approximately 50 years with a 5-year time increment, taking the year 2000 as the baseline. The target year of the study is 2050, which has critical importance in national long-term development planning and climate change research. It also facilitates intercomparison between the results obtained here and from other projects. Simulation results of the year 2005 was used for model validation by comparing with remote sensing maps and potential changes in land use in NEC over 2010-2050 under different scenarios were analyzed. The most common method of model validation is by-pixel comparison between the simulation results and the reference data to calculate the Kappa coefficient of agreement (Vliet et al., 2011). However, this is a rather subjective method of validation (Eitelberg et al., 2015; Vliet et al., 2011). In this study, a more objective method for the model goodness of fit by Costanza (1989) was used. It is based on the measuring of the similarity of patterns and the idea that measurement at one resolution is not sufficient to describe complex patterns of land uses. This method yields indices that summarize the way the fit changes as the resolution of measurement changes. An expanding window is used to gradually degrade the resolution of the comparison.

\subsection{Assessment of ecosystem service values}

The ecosystem service value (ESV) assessment was conducted here to evaluate the impacts of land use changes under different future scenarios. The ecosystem services were divided into supply services, regulating services, cultural services, and support services, following the guidelines of the Millennium Ecosystem Assessment (MA) (Carpenter et al., 2009). Supply services refer to the supply of food products and raw materials. Regulating services include gas release regulation, climate regulation, hydrology regulation, and waste disposal regulation. Cultural services mainly refer to aesthetic value services, while support services improve soil integrity and maintain biodiversity. The ESV is given by the formula:

$$
E S V=\sum\left(A_{k} \times V C_{k}\right)
$$

where $E S V$ is the estimated ecosystem services value, $A_{k}$ is the area $\left(\mathrm{hm}^{2}\right)$, and $V C_{k}$ is the revised ecological value coefficient $\left(\mathrm{RMB} / \mathrm{hm}^{2}\right)$ for land use type $k . V C_{k}$ is calculated as the unit economic value of ecosystem services (Fu et al., 2015). The ecological service value coefficients were adopted in the $E S V$ calculation (Costanza et al., 1997; 2014) (Table 2).

\subsection{Scenario setting and land use requirements}

The widely accepted definition of scenario was given by the IPCC as "a coherent, internally consistent and plausible description of a possible future state of the world" (Parry et al., 1998). In this study, scenarios were set in accordance with the following considerations in NEC: First, NEC is an important region for grain production in China; second, the eco-environment has received much attention due to the presence of large areas of wetland resources; and third, regional economic development in this traditional industrial base has been a national focus. In total, three different future scenarios were defined, which were described as follows: 
Table 2 Equivalent value per unit area of ecosystem services in NEC

\begin{tabular}{llcccccc}
\hline \multicolumn{1}{c}{ Level 1 } & \multicolumn{1}{c}{ Level 2 } & $\begin{array}{c}\text { Crop- } \\
\text { land }\end{array}$ & Forest & Grassland & $\begin{array}{c}\text { Water } \\
\text { body }\end{array}$ & Wetland & $\begin{array}{c}\text { Unused } \\
\text { land }\end{array}$ \\
\hline Supply services & Food production & 1.00 & 0.33 & 0.43 & 0.53 & 0.36 & 0.02 \\
& Production of materials & 0.39 & 2.98 & 0.36 & 0.35 & 0.24 & 0.04 \\
Regulating & Gas release regulation & 0.72 & 4.32 & 1.50 & 0.51 & 2.41 & 0.06 \\
services & Climate regulation & 0.97 & 4.07 & 1.56 & 2.06 & 13.55 & 0.13 \\
& Hydrological adjustment & 0.77 & 4.09 & 1.52 & 18.77 & 13.44 & 0.07 \\
& Waste treatment & 1.39 & 1.72 & 1.32 & 14.85 & 14.4 & 0.26 \\
Cultural services & Provide aesthetic landscape & 0.17 & 2.08 & 0.87 & 4.44 & 4.69 & 0.24 \\
Support ser- & Improve soil integrity & 1.47 & 4.02 & 2.24 & 0.41 & 1.99 & 0.17 \\
vices & Maintain biodiversity & 1.02 & 4.51 & 1.87 & 3.43 & 3.69 & 0.40 \\
\hline
\end{tabular}

(1) Ecological security scenario (ESS): the eco-environment protection in NEC will gain priority. Under this scenario, the areas of forest, grassland, water body, and wetland are increased to improve the eco-environment quality for the region.

(2) Food security scenario (FSS): the increase in food production will be the focus under this scenario. As a result, the areas of cropland increase and the areas of water bodies increase to ensure irrigation for croplands.

(3) Comprehensive development scenario (CDS): there are simultaneous considerations on the requirements for the eco-environment, food security and economic development.

For each scenario, the future demands for land of each land use type were defined in accordance with different government goals (Table 3). The date of land use for each scenario input to the CLUE-S model, and the area and position of each land use type will be controlled to ensure the accuracy of the model simulation.

Table 3 Annual change rate of the area of each land use type under different scenarios (\%)

\begin{tabular}{cccccccc}
\hline & Cropland & Forest & Grassland & Water body & Built-up & Wetland & Unused land \\
\hline ESS & -0.30 & 0.25 & 0.30 & 0.25 & 0.25 & 0.30 & -0.75 \\
FSS & 0.25 & -0.05 & -1.50 & 0.25 & 0.25 & -0.85 & -2.5 \\
CDS & 0.03 & 0.02 & -0.30 & 0.01 & 0.25 & -0.85 & -0.75 \\
\hline
\end{tabular}

\subsection{Data}

A land use map of NEC in 2000 with seven land use types (cropland, forest, grassland, water body, built-up, wetland, and unused land) was used in this study. This map was visually interpreted and verified based on remote sensing data obtained from the Chinese Academy of Sciences (CAS) (Zhang et al., 2014). Biophysical parameters (i.e., aspect, DEM, slope, mean annual precipitation, distance from rivers, distance from roads, distance from residential area, soil type, $\geqslant 0{ }^{\circ} \mathrm{C}$ accumulated temperature, $\geqslant 10^{\circ} \mathrm{C}$ accumulated temperature, and average annual temperature) and socio-economic parameters (population and per capita GDP) were selected as driving factors for land use change. The soil map was obtained from the Chinese Academy of Agricultural Sciences (Ye et al., 2013), with which 20 soil units were delineated under the FAO legend (Ye et al., 2008). Each soil unit was treated as a driving factor in spatial analysis. All gridded data were processed and converted into ASCII grids with a spatial resolution of $1 \mathrm{~km}$. Statistical data were obtained from the China Statistical 
Yearbooks. Land use type and area for 2000-2010 were derived from statistical data, as detailed in Table 4. This study analyzes the driving factors of land use by logistic regression in the year 2000. Statistically significant driving factors of land use are used to construct the simulation model (for details see Xia et al., 2016).

Table 4 Type and source of data

\begin{tabular}{|c|c|c|c|}
\hline Data type & Data name & $\begin{array}{c}\text { Data } \\
\text { format }\end{array}$ & Description and source \\
\hline Land use & Land use basic data & Grid & $\begin{array}{l}\text { Land use resources in seven types of basic data } \\
\text { type of land use, spatial resolution of } 1 \mathrm{~km}\end{array}$ \\
\hline \multirow[t]{9}{*}{ Biophysical } & DEM & Grid & $\begin{array}{l}\text { Institute of Geographic Sciences, CAS, spa- } \\
\text { tial resolution of } 1 \mathrm{~km}\end{array}$ \\
\hline & $\begin{array}{l}\text { Years of average temperature dis- } \\
\text { tribution map }\end{array}$ & Grid & $\begin{array}{l}\text { The national meteorological data compila- } \\
\text { tion, spatial resolution of } 500 \mathrm{~m}\end{array}$ \\
\hline & $\begin{array}{l}\text { Years of average rainfall distribu- } \\
\text { tion map }\end{array}$ & Grid & $\begin{array}{l}\text { The national meteorological data compila- } \\
\text { tion, spatial resolution of } 1 \mathrm{~km}\end{array}$ \\
\hline & $\begin{array}{l}\text { Years of average } \geqslant 0^{\circ} \mathrm{C} \text { accumulated } \\
\text { temperature distribution map }\end{array}$ & Grid & $\begin{array}{l}\text { The national meteorological data compila- } \\
\text { tion, spatial resolution of } 500 \mathrm{~m}\end{array}$ \\
\hline & $\begin{array}{l}\text { Years of average of } \geqslant 10^{\circ} \mathrm{C} \text { accu- } \\
\text { mulated temperature distribution map }\end{array}$ & Grid & $\begin{array}{l}\text { The national meteorological data compila- } \\
\text { tion, spatial resolution of } 500 \mathrm{~m}\end{array}$ \\
\hline & Soil map & Grid & FAO soil classification \\
\hline & $\begin{array}{l}\text { Level } 1-3 \text { traffic network distribu- } \\
\text { tion map }\end{array}$ & Vector & $\begin{array}{l}\text { The national fundamental geographic in- } \\
\text { formation data }\end{array}$ \\
\hline & $\begin{array}{l}\text { Level 1-3 river water distribution } \\
\text { map }\end{array}$ & Vector & $\begin{array}{l}\text { The national fundamental geographic in- } \\
\text { formation data }\end{array}$ \\
\hline & Town centers & Vector & $\begin{array}{l}\text { The national fundamental geographic in- } \\
\text { formation data }\end{array}$ \\
\hline \multirow[t]{2}{*}{ Socio-economic } & Demographic distribution map & Grid & $\begin{array}{l}\text { Institute of Geographic Sciences, CAS, } 1 \\
\mathrm{~km} \text { grid population: people } / \mathrm{km}^{2}\end{array}$ \\
\hline & GDP distribution diagram & Grid & $\begin{array}{l}\text { Institute of Geographic Sciences, CAS, } 1 \\
\mathrm{~km} \text { grid GDP unit: million } \mathrm{RMB} / \mathrm{km}^{2}\end{array}$ \\
\hline Statistical & Area of each land type for $2000-2010$ & Text & China Statistical Yearbooks \\
\hline
\end{tabular}

\section{Results}

\subsection{Land use data validation}

As measurement at one resolution is not sufficient to describe complex patterns, the objective method of Costanza (1989) was used to validate the proposed simulation model, which measures the goodness of fit of the model according to a multiple resolution procedure. The fit for each sampling window is estimated as 1 minus the proportion of cells that would have to be changed to make the sampling windows each have the same number of cells in each category, regardless of their spatial arrangement. As space allocation of the CLUE-S model can better control the area of all types of land use, this study needs to validate the accuracy of space by Costanza's method. The simulation results were compared with the interpreted remote sensing data from 2005 to evaluate model precision with a multiscale, multiresolution analysis method (Figure 3 ). When the validation is tested using the $1 \times 1$ window size, the fit for each sampling accuracy is 0.76 . However, when the test window size is expanded (such as $5 \times 5$ ), it is found that the fit value improves (Figure 3 ). With the continuous expansion of the analysis window, the accuracy of the model improves slightly. The accuracy of 
the CLUE-S model simulation reaches 0.825 . The results indicate that the localized CLUE-S model is better able to simulate the spatial pattern of land use change in NEC.

\subsection{Future changes in land use}

As shown in Figure 4, modeling results of these three scenarios show diverse land use patterns in 2050 compared with those in 2010. In particular, the different land use conversion types in the region of the Khingan Mountains, the Changbai Mountains, the Songnen Plain, the Sanjiang

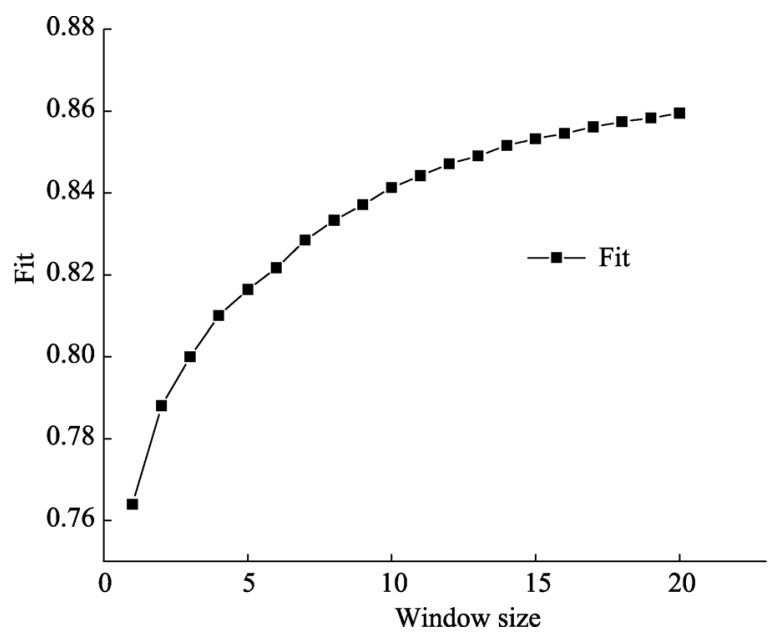

Figure 3 Multiscale simulation test validation

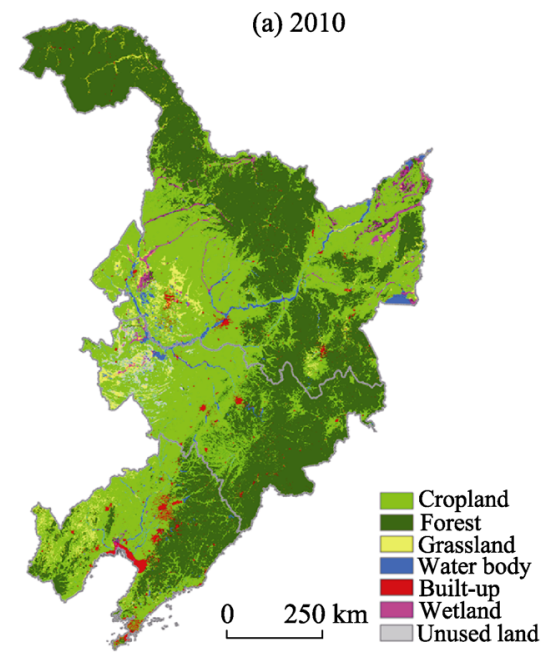

(c) FSS_2050

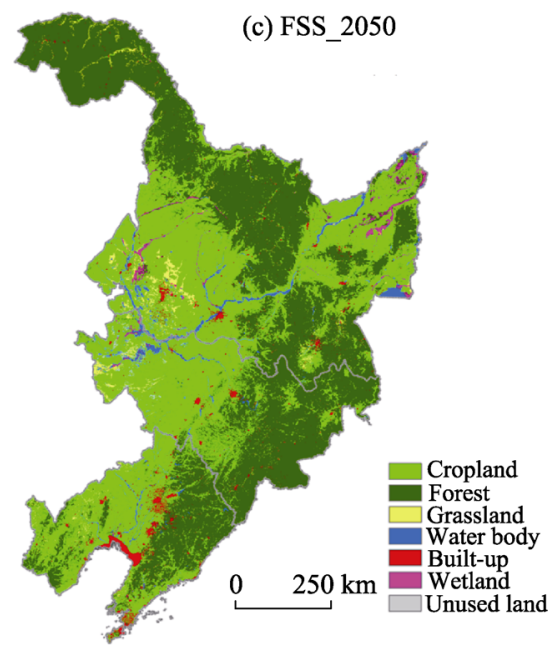

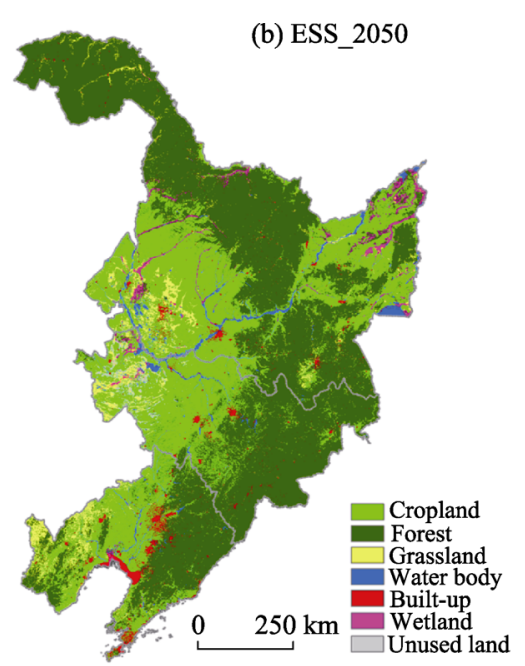

(b) CDS_2050

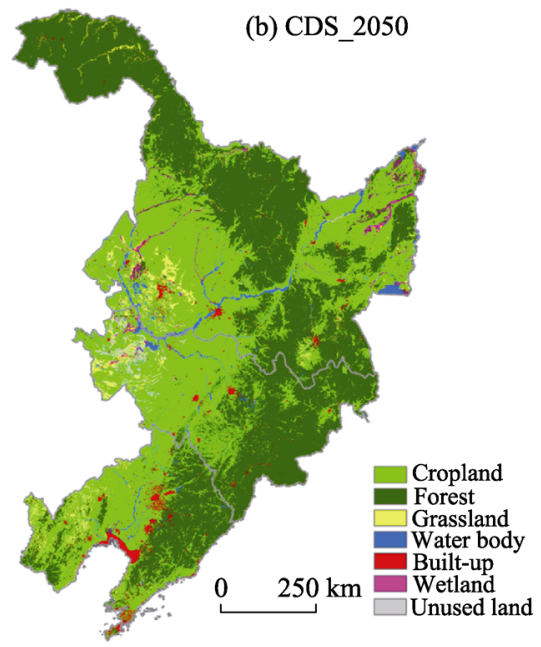

Figure 4 The three scenarios of land use patterns of Northeast China in 2050 
Plain, and the Ruhr Hu Mountains can be seen. The changes are mainly from cropland to other types, such as forest, grassland, or wetland. The spatial patterns and areas of the conversions involving cropland are given in Figure 5 and Table 5, respectively.

Table 5 Cropland and other land use conversion types in the three scenarios $\left(\mathrm{km}^{2}\right)$

\begin{tabular}{|c|c|c|c|c|c|c|c|c|c|c|c|c|}
\hline & & 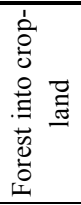 & 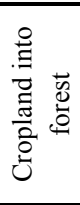 & 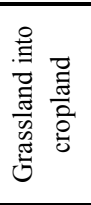 & 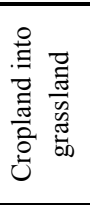 & 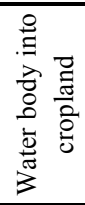 & 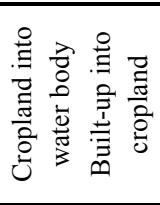 & 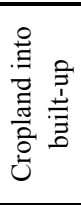 & 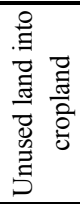 & 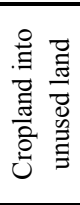 & 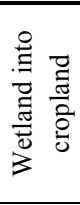 & 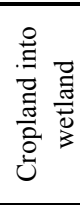 \\
\hline \multirow{4}{*}{ ESS } & $2010-2020$ & & 1005 & & 956 & & 452 & 481 & & & & 141 \\
\hline & 2020-2030 & & 9959 & & 668 & & 451 & 515 & & & & 369 \\
\hline & $2030-2040$ & & 9147 & & 1352 & & 525 & 504 & & & & 458 \\
\hline & $2040-2050$ & & 9044 & & 1359 & & 522 & 523 & & & & 545 \\
\hline \multirow{4}{*}{ FSS } & $2010-2020$ & 1449 & & 4667 & & 14 & & & 1280 & & 612 & \\
\hline & $2020-2030$ & 1493 & & 4363 & & 444 & & & 688 & & 1001 & \\
\hline & 2030-2040 & 1626 & & 3621 & & 272 & & & 1511 & & 973 & \\
\hline & $2040-2050$ & 1581 & & 3750 & & 161 & & & 1509 & & 982 & \\
\hline \multirow{4}{*}{ CDS } & $2010-2020$ & 570 & & & & & & 5 & 519 & & & \\
\hline & $2020-2030$ & 501 & & & & & & 5 & 346 & & 110 & \\
\hline & $2030-2040$ & 495 & & & & & & & 230 & & 313 & \\
\hline & 2040-2050 & 469 & & 32 & & & & & 82 & & 351 & \\
\hline
\end{tabular}

Notes: ESS: Ecological security scenario; FSS: Food security scenario; CDS: Comprehensive development scenario

Under the ESS, ecological protection is achieved by expanding the area of forest, grassland, and wetland. By implementing the policy of returning cropland to forest and grassland, the areas of forest, grassland, and wetland are all enlarged under the ESS scenario. In 2010-2020, cropland is converted to forest $\left(1005 \mathrm{~km}^{2}\right)$ and grassland $\left(956 \mathrm{~km}^{2}\right)$ in the western Changbai Mountains, central Lesser Khingan Mountains, and the Ruhr $\mathrm{Hu}$ Mountains. The changes in 2020-2030 are similar to those of 2010-2020, and most of the conversions occur spatially next to the areas already changed. Cropland, which is a scarce resource in NEC, continues to lose area. From 2030, the decrease in cropland mainly occurs in the Songnen Plain and the Sanjiang Plain, with most of the cropland transformed into forest $\left(18,191 \mathrm{~km}^{2}\right)$ and grassland $\left(2711 \mathrm{~km}^{2}\right)$. In 2010-2050, the speed of the growth of forest area gradually slows, from $1000 \mathrm{~km}^{2} / \mathrm{yr}$ to $900 \mathrm{~km}^{2} / \mathrm{yr}$. In contrast, the speed of the growth area of grassland gradually increases, from $90 \mathrm{~km}^{2} / \mathrm{yr}$ to $135 \mathrm{~km}^{2} / \mathrm{yr}$. Meanwhile, the conversion of cropland to wetland increases from $14 \mathrm{~km}^{2} / \mathrm{yr}$ to $55 \mathrm{~km}^{2} / \mathrm{yr}$.

Under the FSS, the area of cropland increases to ensure future grain security. In 2010-2030, new croplands are mainly distributed in the RuhrHu Mountains and the north of the Songnen Plain. No significant decrease is allowed for forestland in this strictly protected region under the FSS scenario. In 2010-2050, the speed of conversion from forest to cropland is $150 \mathrm{~km}^{2} / \mathrm{yr}$, and conversions mainly occur in the areas that are close to the protected forestland and other scattered areas. Although a large area of grassland is transformed into cropland, the rate decreases in $2010-2050$, from $460 \mathrm{~km}^{2} / \mathrm{yr}$ to $375 \mathrm{~km}^{2} / \mathrm{yr}$, which is still relatively high compared with the conversion between other land use types. To maintain the area of cropland, unused land is transformed into cropland at $70-150 \mathrm{~km}^{2} / \mathrm{yr}$ in the Songnen 
Plain. Meanwhile, wetland is transformed to cropland at a rate of $61-100 \mathrm{~km}^{2} / \mathrm{yr}$ in the Sanjiang Plain.

Under the CDS, ecological security, food security objectives, and economic development goals are comprehensively considered in 2010-2050. New cropland, converted from forest, wetland, and unused land, is mainly distributed in the Songnen Plain, the Sanjiang Plain, and along the Songhua and Nenjiang watersheds. The area of paddy field in the Sanjiang Plain increases considerably, with paddy field expanding and covering the majority of the Sanjiang Plain. In total, an area of $774 \mathrm{~km}^{2}$ of wetland is transformed into cropland in 2010-2050. Newly formed forests are mainly distributed in the Greater Khingan Mountains. The areas of wetland in the Sanjiang Plain and unused land in the Songnen Plain continue to decrease. Due to the effect of topography and local policy, newly formed forests are mainly distributed close to existing forest, which are converted back from cropland and grassland over the next 40 years.
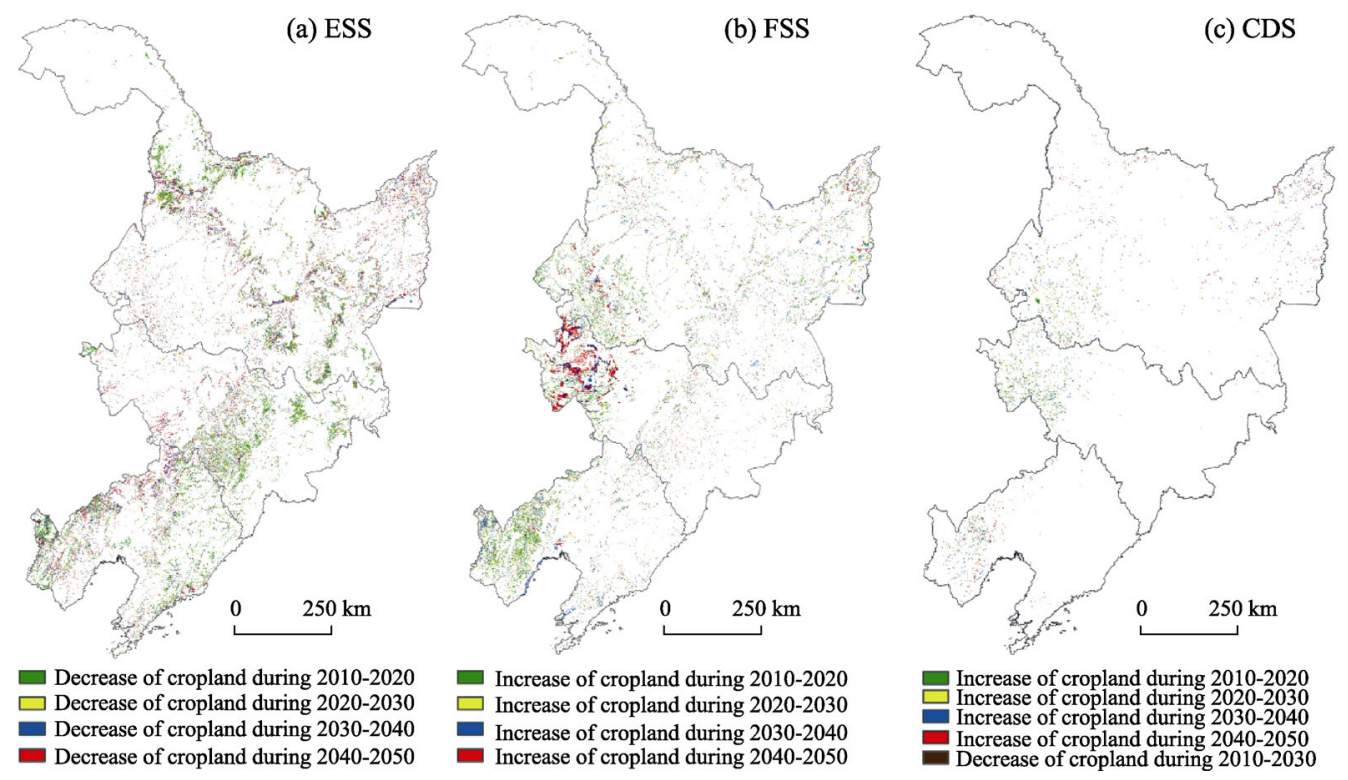

Figure 5 The three scenarios (ESS: Ecological security scenario; FSS: Food security scenario; CDS: Comprehensive development scenario) of cropland conversion in Northeast China in 2010-2050

\subsection{Changes in ecosystems service values}

The ecosystem service value (ESV) from land use change in NEC in 2010-2050 under the three scenarios is calculated using Equation (2) (Figure 6). In 2010-2050, ESV increases under the ESS scenario, and decreases under the FSS and CDS scenarios. The ESV of ESS gradually increases from RMB 2,757,052 million (USD $1=$ RMB 6.5) to RMB 3,040,264 million, and the ESV of FSS gradually declines from RMB 2,757,052 million to RMB 2,658,122 million, while the ESV of CDS gradually declines from RMB 2,757,052 million to RMB 2,656,180 million. Overall, the ESV of both FSS and CDS show a slight decreasing trend. The decrease of the ESV under FSS is relatively less than that under CDS. However, the ESV under ESS shows an increasing trend as a result of the increased area of forest, grassland, wetland, and water body. 
The ESV in NEC is mainly contributed by forest, water body, and wetland for all land use types. As the ecosystem value of forest is relatively high and forest covers about $40 \%$ of the area in NEC, the ESV of forest is relatively large, contributing about $65 \%$ of the total ESV. Although the water body and wetland only account for $2 \%$ of the area in NEC, their contributions to ecosystem services are as high as $18 \%$ and $12 \%$ of the total ESV, respectively. In contrast, although cropland accounts for about $48 \%$ of the area in NEC, it only contributes about $4 \%$ of the total ESV.

ESS guarantees ecological safety and the ESV is mainly composed of forest (RMB 1,966,012 million), wetland (RMB 421,927 million), water body (RMB 538,896 million), and grassland (RMB 34,637 million) in 2050. The ESV of cropland reaches RMB 103,110 million in 2050 under FSS. The newly formed croplands are mainly converted from grassland, forest, and wetland, which is also the reason for the gradual decrease of ESV. Compared with FSS, changes in ESV under CDS are not significant. Under CDS, the value of cropland shows a moderate increasing trend. Compared with FSS, a larger part of the ESV under CDS is from the service value of forest and grassland, while the service value of wetland and water body is relatively small.

Regulating services are the main type of ecosystem service in NEC, followed by support services, supply services, and cultural services. A large part of the ESV is generated by regulating services, and is higher than the combined value of the other three services. Under ESS, regulating services, support services, and cultural services play an important part, and their ESV shows an increasing trend. The services in the FSS scenario indicate a decreasing trend. In particular, regulating services decrease the most, at a rate of $1 \%$ per decade, followed by supply services with a decline of $0.2 \%$. Under CDS, the changes of these four services are quite diverse. Support services indicate a slow declining trend of $0.2 \%$ from 2010 , followed by an increasing trend until 2050. Both regulating and cultural services show slow downward trends.

Comparing all three scenarios, the ESV under ESS is the largest, meaning that ESS has the greatest focus on the eco-environment. FSS is characterized by high values of regulation 
services, and relatively lower values of the supply, support, and cultural services. Under CDS, there is more forest and grassland to improve the ESV. In short, ESS protects forest, grassland, and wetland, and improves the service value of the study area. FSS focuses on the development of cropland, leading to the decrease of ESV in forest, grassland, and wetland. Finally, although CDS is defined according to national long-term development goals, the ESV of CDS is the lowest among the three scenarios.

\section{Discussion}

This study employed a localized variant of the CLUE-S model to simulate the changes in land uses in NEC under three pre-defined scenarios and analyze the impacts of land use changes on ecosystem services. As shown by the modeling results, the selected factors can adequately account for the land use change pattern in NEC. The spatial distribution of the land use types from the modeling results is consistent with the actual conditions in the region. Given the differences between the three scenarios as defined under the guidelines of national policy, it is possible to make some suggestions for future land use policies in NEC. Hopefully, it will guide a coordinated fulfillment of the ecological, food security and socio-economic development goals in the future.

Although the selected parameters are able to simulate the trend of changes under different scenarios, the accuracy of the simulation results can be improved further by fine-tuning model parameters. The fine-tuned CLUE-S model can effectively simulate the land use change over the next 30 years. Although the model has some limitations, better simulation results have been achieved in many parts of the world through adjustment of model parameters. The simulation results are of great significance to the future land use in NEC. At the same time, the model used $1 \mathrm{~km}$ spatial resolution data, however, the simulation accuracy has been controlled for both area and location so as to ensure the accuracy of the final simulation results. As a study of land use change in NEC, the $1 \mathrm{~km}$ spatial resolution data can meet the research needs and reflect the changes in land use. Land use demand is set based on national statistics and future development plans and is thus independent of the CLUE-S model. A better characterization of land use demand using an economic model may lead to useful improvement in the accuracy of the land use predictions. Improvement is also foreseen by including a separate policy factor to quantify the effects of government policies on land use change, which are in most of the times prevailing the combined effects of other driving factors, either natural or socio-economic. Therefore, the CLUE-S model can simulate the land use change under different scenarios in the future. Nevertheless, further methodological developments involving human driving factors and statistical modeling are still necessary to further optimize the simulation accuracy.

This analysis takes advantage of contrasting scenarios in the simulation of land use changes. Under the ESS scenario, the areas of forest, grassland, and wetland clearly increase, leading to eco-environmental improvements. On the other hand, the area of cropland decreases greatly, which threatens the national food security in China. Under the FSS scenario, the areas of cropland and water body increase significantly, which provide enough food for future population development. However, due to decrease in the areas of unused land, grassland and wetland, the eco-environment of the NEC will suffer greatly and sustainable development goals will be hard to achieve. Defined in accordance with the overall objectives 
of sustainable development, the CDS scenario not only protects the forest area and the eco-environment, but also reconciles economic development and food security. Even though the ESS and FSS scenarios are extreme cases which only consider ecological or food security constraints, these two scenarios indicate the direction for balancing ecological, food security, and economic objectives. By comparing the results of ESS and FSS with CDS, further information can be provided for future decision-making. Overall, the CDS scenario is most appropriate to meet the land use targets.

However, LUCC research not only considers the location of newly formed land use types, it also includes the original types of these newly formed land uses into consideration. The goal of land use development in NEC is to balance ecological, food security, and economic development goals. Thus, by studying the transformation of various land use types, we analyzed the ecological value before and after the transformation. This study has not revised all the values involving money with the present value index. It has paid more attention to comparing advantages and disadvantages of each land use scenario with ESV. Under ESS, with the gradual increase in the areas of forest, grassland, and wetland, the ESV increases accordingly and the eco-environment is improved. However, as these environmental friendly land use types are transformed from cropland, the land use intensity decreases. This decrease of cropland leads to food security impacts as the population continues to increase. Thus, ESS is an ideal situation, but one that holds back economic development. Under FSS, to ensure social development, large areas of grassland, forest, and wetland are transformed into cropland. Even though the area of cropland increases significantly, the eco-environment is largely destroyed, and the ESV decreases accordingly. Wetland protection is an important issue in NEC. However, large areas of wetland are transformed into cropland under FSS and CDS. Although NEC has abundant wetland resources, these have been destroyed to different extents in recent years. It would be shortsighted to destroy more wetland for cropland, because the eco-environment would be greatly affected. Compared with ESS and FSS, CDS is set according to the national future land use goals, which comprehensively balance ecological and environmental objectives. Under CDS, land use intensity increases slowly. Surprisingly, the ESV decreases more rapidly under CDS than under FSS; the reason for this is the overuse of unused land and wetland, making the total ESV smaller than under FSS. Even though forest and grassland are protected under CDS, these two land use types only make a small contribution to the total ESV. Under CDS, future resources, which include unused land and wetland, are overdeveloped, leading to a decrease in the ESV. This is an issue that requires careful consideration in the future.

\section{Conclusions}

Future changes in land use and their impacts over 2000-2050 were simulated under three scenarios in NEC. Under the ESS, the areas of forest, grassland, and wetland are expanded. Cropland is converted to forest and grassland in the western Changbai Mountains, central Lesser Khingan Mountains, RuhrHu Mountains, Songnen Plain and the Sanjiang Plain. The speed of the growth in forest and grassland areas is estimated at about $1000 \mathrm{~km}^{2} / \mathrm{yr}$ and 100 $\mathrm{km}^{2} / \mathrm{yr}$, respectively. Under FSS, the cropland area is predicted to increase in the Songnen Plain and the Liaohe Plain. In the Songnen Plain, most of the new croplands will be converted from unused land. In the Sanjiang Plain, wetland will partially be converted to paddy 
fields. In other regions, small areas of scattered forest and grassland will be converted into cropland. New forestland will be developed from the northern Greater Khingan Mountains down to the Lesser Khingan Mountains and further southward to the Changbai Mountains. In addition to the current Forest Nature Reserve in the region, the area of forests will steadily increase. The new forestland will be mainly distributed in the southern Lesser Khingan Mountains. Under the CDS, the change of land use primarily occurs in the Songnen Plain and the Sanjiang Plain. Under the ecological environment scenario, forestland is predicted to increase in the Greater Khingan Mountains and the western Changbai Mountains. Our results also show that even though CDS is defined based on the goals of the regional development plan, the ecological service value for CDS is evaluated at RMB 2,656,180 million in 2050. However, the ESVs of ESS and FSS are evaluated at 3,040,264 million and 2,658,122 million, respectively. Our analysis suggests that CDS is not the optimal development scenario. On the contrary, CDS is the worst scenario for protecting the eco-environment. Local governments are recommended to pay more attention to the protection of the eco-environment in general, and the virgin forestlands and wetlands in the NEC in particular, while implementing the government's land use planning guidelines. It is also advisable to raise the resource use efficiency of various land use types based on scenario results obtained here toward a balanced use of land. More attention should be paid to the protection of the eco-environmental system, so that sustainability is achieved on a solid resource base.

\section{References}

Barreto L, Schoorl J M, Kok K et al., 2013. Modelling potential landscape sediment delivery due to projected soybean expansion: A scenario study of the Balsas sub-basin, Cerrado, Maranhão state, Brazil. Journal of Environmental Management, 115: 270-277.

Bonilla-Moheno M, Aide T M, Clark M, 2012. The influence of socioeconomic, environmental, and demographic factors on municipality-scale land-cover change in Mexico. Regional Environmental Change, 12(3): $543-557$.

Carpenter S R, Mooney H A, Agard J et al., 2009. Science for managing ecosystem services: Beyond the millennium ecosystem assessment. Proceedings of the National Academy of Sciences, 106(5): 1305-1312.

Chen C, Qian C, Deng A et al., 2012. Progressive and active adaptations of cropping system to climate change in Northeast China. European Journal of Agronomy, 38: 94-103.

Chen L, Wang J, Fu B et al., 2001. Land-use change in a small catchment of northern Loess Plateau, China. $A g-$ riculture, Ecosystems \& Environment, 86(2): 163-172.

Costanza R, 1989. Model goodness of fit: A multiple resolution procedure. Ecological Modelling, 47(3/4): 199-215.

Costanza R, D'Arge R, de Groot R et al., 1997. The value of the world's ecosystem services and natural capital. Nature, 387(6630): 253-260.

Costanza R, de Groot R, Sutton P et al., 2014. Changes in the global value of ecosystem services. Global Environmental Change, 26: 152-158.

David B L A C, 2007. Global scale climate-crop yield relationships and the impacts of recent warming. Environmental Research Letters, 2(1): 14002.

Duan P, Qin L, Wang Y et al., 2016. Spatial pattern characteristics of water footprint for maize production in Northeast China. Journal of the Science of Food and Agriculture, 96(2): 561-568.

Eitelberg D A, Vliet J, Verburg P H, 2015. A review of global potentially available cropland estimates and their consequences for model-based assessments. Global Change Biology, 21(3): 1236-1248.

$\mathrm{Fu} \mathrm{B}$, Zhang L, Xu Z et al., 2015. Ecosystem services in changing land use. Journal of Soils and Sediments, 15(4): 833-843.

Geoghegan J, Villar S C, Klepeis P et al., 2001. Modeling tropical deforestation in the southern Yucatán peninsular region: Comparing survey and satellite data. Agriculture, Ecosystems \& Environment, 85(1-3): 25-46.

Jiang W, Chen Z, Lei X et al., 2016. Simulation of urban agglomeration ecosystem spatial distributions under different scenarios: A case study of the Changsha-Zhuzhou-Xiangtan urban agglomeration. Ecological Engi- 
neering, 88: 112-121.

Lambin E F, Meyfroidt P, 2011. Global land use change, economic globalization, and the looming land scarcity. Proceedings of the National Academy of Sciences, 108(9): 3465-3472.

Letourneau A, Verburg P H, Stehfest E, 2012. A land-use systems approach to represent land-use dynamics at continental and global scales. Environmental Modelling \& Software, 33: 61-79.

Li Z, Tang H, Yang P et al., 2012. Spatio-temporal responses of cropland phenophases to climate change in Northeast China. Journal of Geographical Sciences, 22(1): 29-45.

Liu J, Deng X, 2010. Progress of the research methodologies on the temporal and spatial process of LUCC. Chinese Science Bulletin, 55(14): 1354-1362.

Parry M, Arnell N, Hulme M et al., 1998. Adapting to the inevitable. Nature, 395: 741.

Roy P, Roy A, Joshi P et al., 2015. Development of decadal (1985-1995-2005) land use and land cover database for India. Remote Sensing, 7(3): 2401-2430.

Serneels S, Lambin E F, 2001. Proximate causes of land-use change in Narok District, Kenya: A spatial statistical model. Agriculture, Ecosystems \& Environment, 85(1-3): 65-81.

Shearer A W, 2005. Approaching scenario-based studies: Three perceptions about the future and considerations for landscape planning. Environment and Planning B: Planning and Design, 32: 67-87.

Song W, Deng X, Yuan Y et al., 2015. Impacts of land-use change on valued ecosystem service in rapidly urbanized North China Plain. Ecological Modelling, 318: 245-253.

Stürck J, Schulp C J E, Verburg P H, 2015. Spatio-temporal dynamics of regulating ecosystem services in Europe: The role of past and future land use change. Applied Geography, 63: 121-135.

Tian L, 2015. Land use dynamics driven by rural industrialization and land finance in the peri-urban areas of China: The examples of Jiangyin and Shunde. Land Use Policy, 45: 117-127.

van Vliet J, Bregt A K, Hagen-Zanker A, 2011. Revisiting kappa to account for change in the accuracy assessment of land-use change models. Ecological Modelling, 222(8): 1367-1375.

van Vliet J, Hagen-Zanker A, Hurkens J et al., 2013. A fuzzy set approach to assess the predictive accuracy of land use simulations. Ecological Modelling, 261/262: 32-42.

Verburg P, Berkel D, Doorn A et al., 2010. Trajectories of land use change in Europe: A model-based exploration of rural futures. Landscape Ecology, 25(2): 217-232.

Verburg P H, Overmars K P, 2009. Combining top-down and bottom-up dynamics in land use modeling: Exploring the future of abandoned farmlands in Europe with the dyna-CLUE model. Landscape Ecology, 24(9): 1167-1181.

Verburg P H, Rounsevell M D A, Veldkamp A, 2006. Scenario-based studies of future land use in Europe. Agriculture, Ecosystems \& Environment, 114(1): 1-6.

Verburg P H, Soepboer W, Veldkamp A et al., 2002. Modeling the spatial dynamics of regional land use: The CLUE-S model. Environmental Management, 30(3): 391-405.

Wang M, Xiong Z, Yan X, 2015. Modeling the climatic effects of the land use/cover change in eastern China. Physics and Chemistry of the Earth, Parts $A / B / C, 87 / 88: 97-107$.

Wang Z, Zhang B, Zhang S et al., 2006. Changes of land use and of ecosystem service values in Sanjiang Plain, Northeast China. Environmental Monitoring and Assessment, 112(1-3): 69-91.

Xia T, Wu W, Zhou Q et al., 2014. Spatio-temporal changes in the rice planting area and their relationship to climate change in Northeast China: A model-based analysis. Journal of Integrative Agriculture, 13(7): 1575-1585.

Xia T, Wu W, Zhou Q et al., 2016. Model-based analysis of spatio-temporal changes in land use in Northeast China. Journal of Geographical Sciences, 26(2): 171-187.

Xu G, Huang X, Zhong T et al., 2015. Assessment on the effect of city arable land protection under the implementation of China's national general land use plan (2006-2020). Habitat International, 49: 466-473.

Ye L, Tang H, Zhu J et al., 2008. Spatial patterns and effects of soil organic carbon on grain productivity assessment in China. Soil Use and Management, 24(1): 80-91.

Ye L, Xiong W, Li Z et al., 2013. Climate change impact on China food security in 2050. Agronomy for Sustainable Development, 33(2): 363-374.

Zhang F, Tiyip T, Feng Z D et al., 2015. Spatio-temporal patterns of land use/cover changes over the past 20 years in the middle reaches of the Tarim River, Xinjiang, China. Land Degradation \& Development, 26(3): 284-299.

Zhang X, Xiong Z, Zhang X et al., 2016. Using multi-model ensembles to improve the simulated effects of land use/cover change on temperature: A case study over Northeast China. Climate Dynamics, 46(3/4): 765-778.

Zhang Z, Wang X, Zhao X et al., 2014. A 2010 update of national land use/cover database of China at 1:100000 scale using medium spatial resolution satellite images. Remote Sensing of Environment, 149(149): 142-154. 